JURNAL RISET REKAYASA ELEKTRO

Vol.3, No.2, Desember 2021, Hal. 91 100

P-ISSN: 2685 - $4341 \quad$ E-ISSN : 2685-5313

\title{
Rancang Bangun Sistem Monitoring Kelembaban Dan Suhu Tanah Untuk Tanaman Bawang Merah Di Kabupaten Brebes
}

\author{
Sigit Rizky Pratama ${ }^{1}$, Dian Nova Kusuma Hardani ${ }^{2}$ \\ Program Studi S1 Teknik Elektro, Universitas Muhammadiyah Purwokerto \\ Fakultas Teknik dan Sains, Universitas Muhammadiyah Purwokerto
}

\begin{tabular}{l}
\hline Informasi Makalah \\
\hline Dikirim, 21 Agustus 2021 \\
Direvisi, 29 Novemeber 2021 \\
Diterima, 30 November 2021
\end{tabular}

\section{Kata Kunci:}

Bawang Merah

Mikrokontroler Arduino Nano

Kelembaban Tanah

DS18B20

\begin{abstract}
INTISARI
Tanaman bawang merah merupakan salah satu kebutuhan pokok. Benih bawang merah yang baik adalah yang tumbuh secara optimal yang dipengaruhi beberapa faktor, antara lain presentase kelembaban dan suhu tanah. Syarat tumbuh optimal benih bawang merah harus ditanam pada tempat yang kelembaban dan suhu tanahnya sesuai dengan yang dibutuhkan benih bawang merah. Berkembangnya teknologi saat ini dimungkinkan membuat sebuah teknologi dibidang pertanian. Pada penelitian ini dikembangkan sistem monitoring kelembaban dan suhu tanah dengan media penyiraman. Alat ini berfungsi untuk mengukur dan menormalkan kelembaban dan suhu tanah untuk tanaman bawang merah. Pengukuran kelembaban tanah menggunakan sensor kelembaban tanah, pengukuran suhu tanah menggunakan sensor DS18B20. Sistem ini menggunakan Arduino Nano sebagai penggerak utama. Cara kerja alat ini adalah saat sensor kelembaban tanah mendeteksi kelembaban di bawah 50\% maka mikrokontroler akan mengaktifkan water pump, saat sensor mengukur kelembaban tanah diatas $70 \%$ maka mikrokontroler akan memberi perintah water pump off. Seluruh informasi menghidupkan dan mematikan water pump akan ditampilkan pada LCD. Hasil penelitian menunjukkan apabila kelembaban yang dibaca oleh sensor soil moisture di bawah 50\% maka water pump akan menyala, dan jika data pengukuran sudah mencapai $70 \%$ maka water pump akan berhenti. Jenis tanah yang cocok untuk tanaman bawang merah adalah tanah aluvial yang tidak mudah kering sehingga nilai kelembaban tanah lebih stabil.
\end{abstract}

\section{ABSTRACT}

Shallot plants are one of the basic needs. A good shallot seed grows optimally, which is influenced by several factors, including the percentage of moisture and soil temperature. The conditions for optimal growth of shallot seeds must be planted in a place where the humidity and temperature of the soil follow the requirements of the shallot seeds. The development of technology is currently possible to make technology in agriculture. In this study, a monitoring system for soil moisture and temperature was developed using water media. This tool serves to measure and normalize soil moisture and temperature for shallot plants. Measurement of soil moisture using a soil moisture sensor, soil temperature measurement using a DS18B20 sensor. This system uses Arduino Nano as the prime mover. This tool works when the soil moisture sensor detects humidity below $50 \%$, and the microcontroller will activate the water pump. The microcontroller will give the water pump off command when the sensor measures soil moisture above $70 \%$. All information on and off the water pump will be displayed on the LCD. The results show that if the humidity read by the soil moisture sensor is below $50 \%$, the water pump will turn on, and if the measurement data has reached $70 \%$, the water pump will stop. The type of soil suitable for onion plants is alluvial soil that is not easy to dry so that the soil moisture value is more stable.

\section{Korespondensi Penulis:}

Sigit Rizky Pratama

Program Studi Teknik Elektro

Fakultas Teknik dan Sains Universitas Muhammadiyah Purwokerto

JL. Raya Dukuhwaluh, Purwokerto, 53182

Email: $\underline{\text { sigitrizky98@gmail.com }}$ 


\section{PENDAHULUAN}

Bawang merah (Allium ascalonicum L.) merupakan bahan pokok, namun konsumen rumah tangga juga dapat menggunakan bawang merah sebagai bumbu tambahan dalam masakan sehari-hari. Penggunaan bawang merah telah ditemukan dalam pengobatan tradisional dan manfaatnya telah diterima oleh masyarakat luas. Pertumbuhan industri pangan akhir-akhir ini juga mendorong permintaan bawang merah yang sangat besar di dalam negeri[1].

Saat ini terjadi pertumbuhan teknologi di bidang pertanian yang sangat pesat. Salah satu contohnya adalah sistem pemantauan dan pengontrolan budidaya bawang merah. Sistem ini digunakan untuk meningkatkan hasil pertanian. Tingkat hasil dapat menurun karena banyak faktor, salah satunya adalah rigasi yang tidak teratur atau irigasi yang berlebihan merupakan salah satu faktor utama yang menyebabkan penurunan hasil. Jadi sistem pemantauan yang dikembangkan terutama berfokus pada prediksi kelembaban tanah serta sekitarnya suhu yang sesuai untuk tanaman. Sistem yang di kembangkan hampir memprediksi awal perubahan kelembaban tanah dan suhu [2].

Perbedaan hasil setiap variates/kultivar tidak hanya tergantung pada sifatnya, tetapi juga sangat tergantung pada lingkungan dan kondisi daerah. Iklim, pemupukan, pengairan, kelembaban dan suhu tanah merupakan penentu hasil dan kualitas bawang merah [3].

Di Indonesia bawang merah dapat ditanam di dataran rendah sampai ketinggian $1000 \mathrm{~m}$ di atas permukaan laut. Ketinggian tempat yang optimal untuk pertumbuhan dan perkembangan bawang merah adalah 0-450 $\mathrm{m}$ di atas permukaan laut [4].

Seiring berkembangnya zaman pengukuran yang terintegrasi termasuk salah satu dari perkembangan teknologi dan elektronika saat ini. Pengukuran merupakan hal yang sangat penting dalam dunia ilmu pengetahuan khususnya di dalam ilmu teknik. Pengukuran dalam ilmu teknik digunakan sebagai sistem proteksi atau sistem kendali suatu proses. Pengukuran berperan penting dalam membantu pekerjaan manusia dan memberikan manfaat kemudahan bagi para teknisi dalam menentukan nilai besaran suatu kuantitas atau variable [5].

\section{METODE PENELITIAN}

\subsection{Alur Penelitian}

Dalam melakukan kegiatan penelitian ini, ada beberapa tahapan yang diperlukan untuk mendapatkan hasil yang diinginkan dan tahapan-tahapan alur penelitian dapat dilihat pada Gambar 1 berikut.

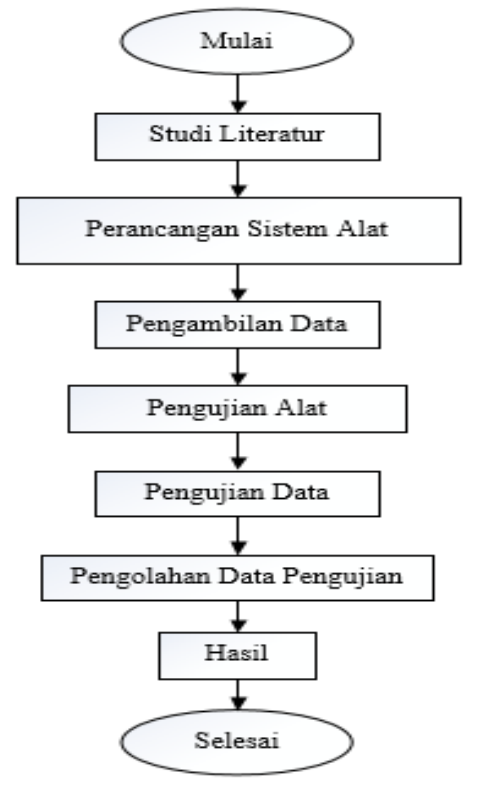

Gambar 1. Diagram Alur Penelitian

Langkah awal dalam memulai penelitian yaitu mempelajari literatur yang berkaitan dengan perancangan sistem yang dibuat. Tahapan kedua adalah perancangan sistem alat yaitu merancang bagianbagian komponen yang membentuk sistem. Perancangan ini dimulai perbagian dari pemprograman mikrokontroler, sensor kelembaban, dan sensor suhu tanah, dan menampilkan hasil yang diproses oleh system melalui layar LCD. Pengambilan data kelembaban dan suhu tanah dilakukan pada jenis tanah yang berbeda. Kemudian, data dari masing-masing setiap jenis tanah akan tertampilkan pada layar LCD dengan 
ketentuan batas kelembaban tanah $50-70 \%$ dan batas suhu tanah $25^{\circ} \mathrm{C}-32^{\circ} \mathrm{C}$. Sistem diuji cobakan langsung pada berbagai jenis tanah agar diperoleh jenis tanah yang sesuai serta untuk mengetahui apakah alat ini mampu mengukur kelembaban dan suhu tanah untuk tanaman bawang merah. Setelah sitem dirancang dan diuji coba, maka langkah selanjutnya adalah pengujian data. Pengujian ini digunakan untuk mengetahui seberapa akurat sensor kelembaban dan sensor suhu tanah yang digunakan. Data hasil pengujian tersebut diolah sesuai dengan literatur dan teori-teori yang telah ada pada penelitian sebelumnya. Pada tahapan ini data yang telah didapat juga dianalisis dengan membandingkan data dari kelembaban dan suhu dari dua jenis tanah yaitu tanah aluvial dan tanah latosol. Data hasil yang ditampilkan pada layar LCD menentukan cocok atau tidak tanah tersebut untuk ditanam tanaman bawang merah.

\subsection{Alat dan Bahan}

1. Peralatan hardware yang digunakan :
a. Kabel USB
b. Multimeter
c. Solder
d. PC atau Laptop.

2. Peralatan software yang digunakan :
a. Arduino IDE
b. Fritzing.

3. Bahan yang digunakan :
a. Arduino nano
b. Sensor Suhu Tanah DS18B20
c. Soil Moisture Sensor
d. LCD (Liquid Crystal Display)
e. Tinol
f. Box komponen
g. Power Supply 12V
h. Resistor 10k Ohm
i. Mosfet Module
j. Project Circuit Board
k. Push Button
1. Kabel Jumper
m. Springkel mini
n. Tabung Air mini.

\subsection{Diagram Blok Sistem}

Dalam melakukan kegiatan penelitian ini, ada beberapa dalam perancangan sistem yang diinginkan dan tahapan-tahapan diagram blok sistem dapat dilihat pada Gambar 2 berikut.

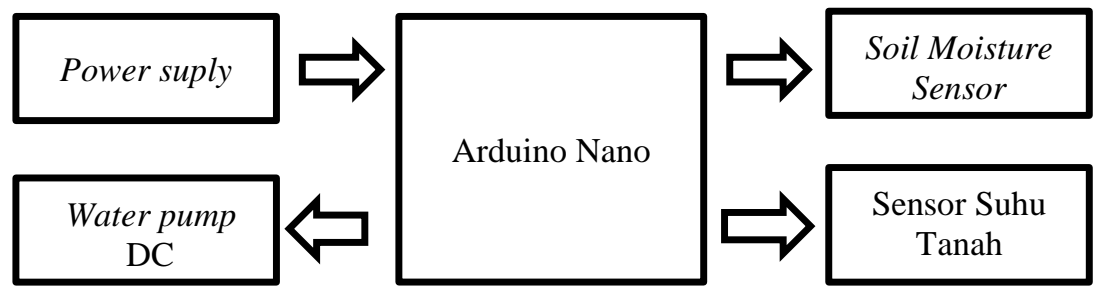

Gambar 2. Diagram Blok Sistem

Arduino Nano adalah pusat kendali dari semua sistem perangkat yang ada. Sensor yang digunakan adalah sensor kelembaban, sensor suhu DS18B20. Power supply digunakan untuk mensuplai arus listrik yang digunakan untuk menjalankan semua sistem dan water pump dc digunakan untuk media penyiram saat nilai kandungan air bersifat kering.

Gambar 2 pada diagram blok sistem menyatakan bahwa setelah sistem diaktifkan maka dilakukan setpoint kelembaban tanah dan suhu tanah yang dibutuhkan oleh tanaman bawang merah. Sensor kelembaban akan langsung bekerja mendeteksi kelembaban pada lingkungan sekitar. Hasil dari pembacaan sensor tersebut akan diolah oleh mikrokontroler dan langsung di tampilkan di LCD. 


\section{HASIL DAN PEMBAHASAN}

\subsection{Hasil Pengujian Sistem}

\subsubsection{Pengujian Power Supply}

Pengujian power supply dilakukan untuk mengetahui berapa tegangan listrik DC yang dihasilkan power supply sebagai sumber tegangan semua komponen yang terpasang pada alat ini, dari hasil pengujian didapatkan tegangan sebesar $12,17 \mathrm{v}$ seperti pada Gambar 3 nantinya dapat mensuplai modul mosfet sebagai driver water pump setelah itu tegangan diturunkan dengan buck konverter dan akan diturunkan tegangan semula $12,17 \mathrm{v}$ menjadi $5,1 \mathrm{v}$ setelah tegangan diturunkan maka sudah dapat untuk mensuplai beberapa komponen seperti arduino nano, sensor kelembaban, sensor DS18B20.

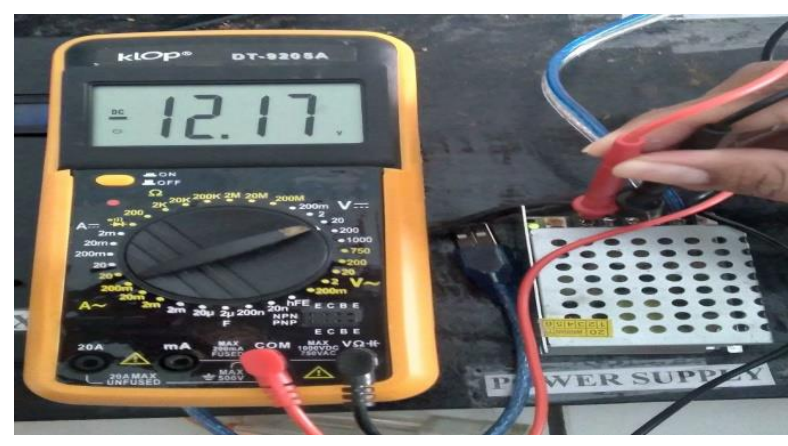

Gambar 3. Pengujian power supply

\subsubsection{Pengujian Board Arduino Nano}

Pada Tabel 1 hasil menunjukkan pengukuran pada tegangan input maupun output pin Arduino Nano, penggunaan pin analog A4, A5, A7 menghasilkan tegangan 4,94 Volt dan pin digital D5 dan D6 menghasilkan tegangan 4,99 Volt. Pin tersebut adalah pin output yang dibutuhkan pada Arduino Nano maka menghasilkan nilai tegangan yang lebih tinggi, dengan menghasilkan tegangan yang sesuai maka sistem pada output Arduino Nano bekerja stabil.

Tabel 1 Pengujian tegangan input pin Arduino Nano

\begin{tabular}{cccc}
\hline No & $\begin{array}{c}\text { Tegangan } \\
\text { Power supply (Volt) }\end{array}$ & $\begin{array}{c}\text { Input Pin Analog dan } \\
\text { Digital }\end{array}$ & $\begin{array}{c}\text { Hasil Pengukuran } \\
\text { VDC (Volt) }\end{array}$ \\
\hline 1 & 12 & A4 & 4,94 \\
2 & 12 & A5 & 4,94 \\
3 & 12 & A7 & 4,94 \\
4 & 12 & D5 & 4,99 \\
5 & 12 & D6 & 4,99 \\
\hline
\end{tabular}

\subsubsection{Pengujian Sensor Kelembaban}

Hasil pengukuran tegangan keluaran sensor kelembaban tanah dapat dilihat pada Tabel 2. Pada saat terjadi perubahan nilai kelembaban tanah, tegangan sensor cenderung stabil. Oleh karena itu, hal ini dapat dikatakan bahwa sensor kelembaban tanah bekerja stabil.

Tabel 2. Pengujian tegangan sensor kelembaban tanah

\begin{tabular}{cccc}
\hline No & Kelembaban (\%) & Output Tegangan (Volt) & Keterangan \\
\hline 1 & 42 & 2,24 & Terkoneksi \\
2 & 48 & 2,15 & Terkoneksi \\
3 & 66 & 1,99 & Terkoneksi \\
4 & 77 & 1,85 & Terkoneksi \\
5 & 89 & 1,61 & Terkoneksi \\
\hline
\end{tabular}

\subsubsection{Pengujian Sensor Suhu DS18B20}

Perbandingan nilai suhu pada sensor DS18B20 dan Thermometer dilihat pada Tabel 3. Pengukuran tegangan sensor suhu dilakukan sebanyak 5 kali dengan nilai suhu yang berbeda. Hasil menunjukkan bahwa nilai tegangan sensor tetap, sehingga sensor suhu bekerja stabil. 
Tabel 3. Hasil pengujian tegangan sensor suhu DS18B20

\begin{tabular}{cccc}
\hline No & Suhu $\left({ }^{\circ} \mathrm{C}\right)$ & $\begin{array}{c}\text { Output Tegangan } \\
(\text { Volt })\end{array}$ & Keterangan \\
\hline 1 & 27,87 & 4,98 & Terkoneksi \\
2 & 29,75 & 4,99 & Terkoneksi \\
3 & 30,62 & 4,99 & Terkoneksi \\
4 & 31,31 & 4,98 & Terkoneksi \\
5 & 32,56 & 4,99 & Terkoneksi \\
\hline
\end{tabular}

\subsubsection{Pengujian Tampilan LCD}

Rangkaian LCD dihubungkan dari kaki pin SDA LCD dengan A4 Arduino nano, kaki pin SCL LCD dihubungkan dengan A5 Arduino nano, kaki pin VCC LCD dihubungkan dengan 5V Arduino nano, dan Ground LCD dihubungkan dengan Ground Arduino nano, yang merupakan pin I/O fungsi khusus, sebagai pengirim data secara serial. Sehingga nilai yang tampil pada LCD display akan dapat dikendalikan oleh Mikrokontroler Arduino nano. Pada bagian ini mikrokontroler akan memberi data langsung ke LCD. Pada LCD I2C sudah tedapat driver untuk mengubah data ASCII output pada mikrokontroler menjadi tampilan karakter. Pengujian rangkaian LCD dilakukan dengan memberikan program pada mikrokontroler untuk menampilkan karakter pada display LCD. Pengujian tampilan LCD dapat dilihat pada Gambar 4 berikut.

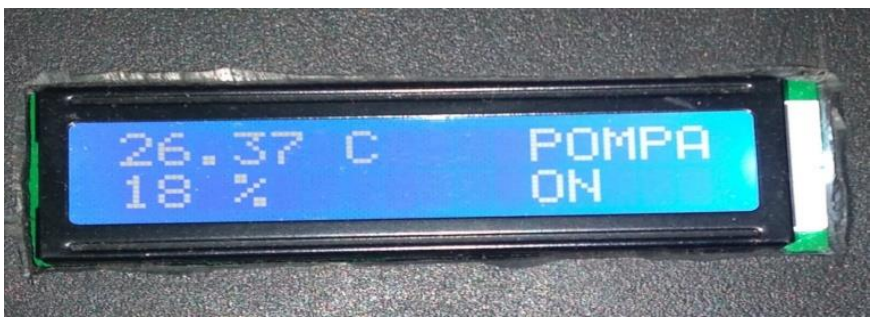

Gambar 4. Pengujian tampilan LCD

\subsection{Analisis Hasil Pengukuran}

Pengukuran dibuat langsung dengan membandingkan nilai pada 2 jenis tanah yang berbeda dengan nilai alat yang dibuat, pengukuran dilakukan dengan mengukur kelembaban tanah dan suhu tanah pada pembibitan tanaman bawang merah dengan menggunakan sensor soil moisture dan sensor DS18B20.

\subsubsection{Hasil pengukuran tanah aluvial}

Hasil pengukuran dari jenis tanah aluvial dapat dilihat pada Tabel 4. Saat alat hidup, sistem akan meminta input kelembaban tanah dan suhu tanah pada tanaman bawang merah yang dideteksi oleh kedua sensor tersebut dikirimkan ke system. Perintah pada mikrokontroler untuk mengaktifkan pompa air, dimana output yaitu pompa air hidup atau mati. Jika kelembaban tanah <50\%, maka sistem akan melakukan penyiraman pada tanaman bawang merah. Jika kelembaban tanah $>50 \%$, maka sistem tidak akan melakukan penyiraman pada tanaman bawang merah.

Tabel 4. Hasil pengukuran tanah aluvial

\begin{tabular}{|c|c|c|c|c|}
\hline No & Waktu Percobaan & Kelembaban Tanah (\%) & Suhu Tanah $\left({ }^{\circ} \mathrm{C}\right)$ & Pompa \\
\hline \multirow{2}{*}{1} & \multirow{2}{*}{$08.00 \mathrm{WIB}$} & Percobaan $1=37 \%$ & Percobaan $1=28,12^{\circ} \mathrm{C}$ & $\mathrm{ON}$ \\
\hline & & Percobaan $2=69 \%$ & Percobaan $2=28,12^{\circ} \mathrm{C}$ & OFF \\
\hline \multirow{2}{*}{2} & \multirow{2}{*}{$09.00 \mathrm{WIB}$} & Percobaan $1=49 \%$ & Percobaan $1=31,94^{\circ} \mathrm{C}$ & $\mathrm{ON}$ \\
\hline & & Percobaan $2=68 \%$ & Percobaan $2=31,50 \mathrm{C}$ & OFF \\
\hline \multirow{2}{*}{3} & \multirow{2}{*}{$10.00 \mathrm{WIB}$} & Percobaan $1=47 \%$ & Percobaan $1=30,33^{\circ} \mathrm{C}$ & ON \\
\hline & & Percobaan $2=72 \%$ & Percobaan $2=30,00^{\circ} \mathrm{C}$ & $\mathrm{OFF}$ \\
\hline \multirow{2}{*}{4} & \multirow{2}{*}{$11.00 \mathrm{WIB}$} & Percobaan $1=48 \%$ & Percobaan $1=33,67^{\circ} \mathrm{C}$ & $\mathrm{ON}$ \\
\hline & & Percobaan $2=77 \%$ & Percobaan $2=33,56^{\circ} \mathrm{C}$ & $\mathrm{OFF}$ \\
\hline \multirow{2}{*}{5} & \multirow{2}{*}{$12.00 \mathrm{WIB}$} & Percobaan $1=48 \%$ & Percobaan $1=35,00^{\circ} \mathrm{C}$ & $\mathrm{ON}$ \\
\hline & & Percobaan $2=73 \%$ & Percobaan $2=34,94^{\circ} \mathrm{C}$ & $\mathrm{OFF}$ \\
\hline No & Waktu Percobaan & Kelembaban Tanah (\%) & Suhu Tanah $\left({ }^{\circ} \mathrm{C}\right)$ & Pompa \\
\hline \multirow{2}{*}{6} & \multirow{2}{*}{$13.00 \mathrm{WIB}$} & Percobaan $1=40 \%$ & Percobaan $1=31,81^{\circ} \mathrm{C}$ & ON \\
\hline & & Percobaan $2=78 \%$ & Percobaan $2=31,62^{\circ} \mathrm{C}$ & $\mathrm{OFF}$ \\
\hline 7 & $14.00 \mathrm{WIB}$ & Percobaan $1=46 \%$ & Percobaan $1=29,37^{\circ} \mathrm{C}$ & $\mathrm{ON}$ \\
\hline
\end{tabular}




\begin{tabular}{ccllc}
\hline & & & & \\
\hline & & Percobaan $2=66 \%$ & Percobaan $2=29,31^{\circ} \mathrm{C}$ & OFF \\
& \multirow{2}{*}{$15.00 \mathrm{WIB}$} & Percobaan $1=48 \%$ & Percobaan $1=28,19^{\circ} \mathrm{C}$ & ON \\
& & Percobaan $2=74 \%$ & Percobaan $2=28,12^{\circ} \mathrm{C}$ & OFF \\
& \multirow{2}{*}{$16.00 \mathrm{WIB}$} & Percobaan $1=47 \%$ & Percobaan $1=27,69^{\circ} \mathrm{C}$ & ON \\
& & Percobaan $2=75 \%$ & Percobaan $2=27,50^{\circ} \mathrm{C}$ & OFF \\
\multirow{2}{*}{10} & \multirow{2}{*}{$17.00 \mathrm{WIB}$} & Percobaan $1=49 \%$ & Percobaan $1=27,25^{\circ} \mathrm{C}$ & ON \\
& & Percobaan $2=61 \%$ & Percobaan $2=27,20^{\circ} \mathrm{C}$ & OFF \\
\hline
\end{tabular}

Perbandingan hasil presentase kelembaban tanah dapat ditunjukkan pada Gambar 5. Hasil pengujian untuk kelembaban jenis tanah Aluvial menurun dengan bertambahnya waktu. Dengan dilakukan penyiraman, nilai kelembaban tanah akan naik sesuai kebutuhan tanaman.

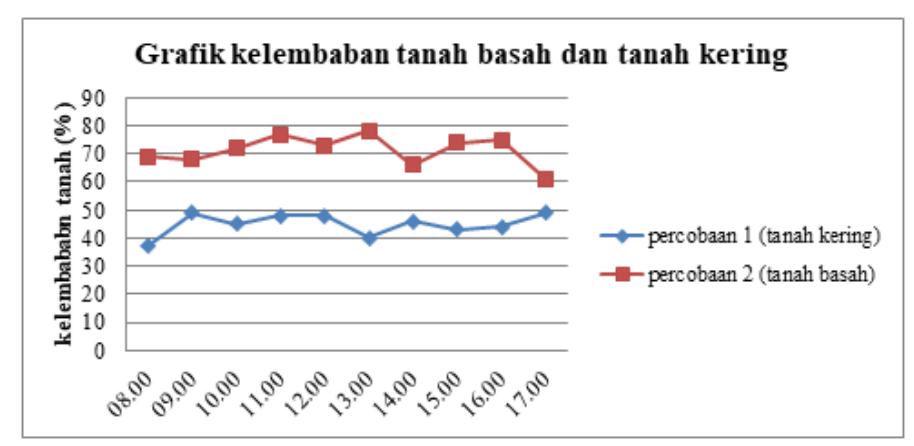

Gambar 5. Grafik kelembaban tanah basah dan tanah kering

Perbandingan hasil presentase suhu tanah dapat ditunjukkan pada Gambar 6. Hasil pengukuran untuk perubahan suhu yang terkandung pada tanah mengalami perbedaan. Pada saat percobaan 1 (tanah bersifat kering) suhu lebih besar nilainya dibandingkan saat percobaan 2 (tanah bersifat basah) maka suhu yang terkandung pada tanah turun.

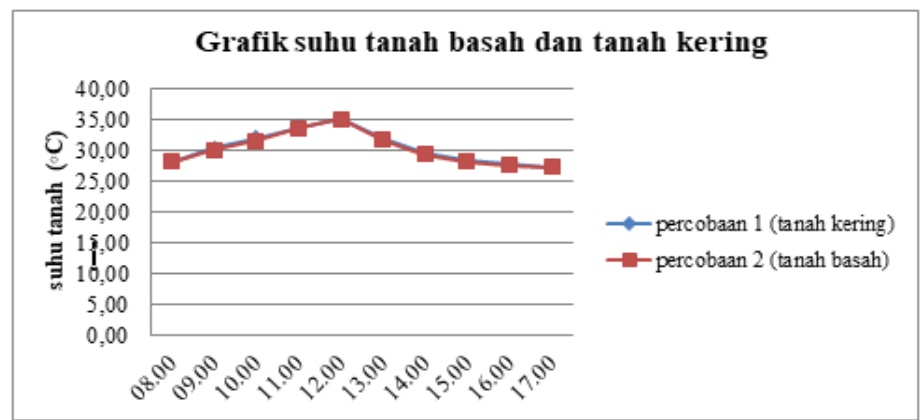

Gambar 6. Grafik suhu tanah basah dan tanah kering

\subsubsection{Hasil pengukuran tanah latosol}

Langkah pengukuran pada tanah latosol juga sama dengan pengukuran pada tanah aluvial. Dengan melalukan pengaturan pada mikrokontroller. Jika kelembaban tanah <50\%, maka sistem akan melakukan penyiraman pada tanaman bawang merah. Jika kelembaban tanah $>50 \%$, maka sistem tidak akan melakukan penyiraman. Hasil pengukuran dari jenis tanah latosol dapat dilihat pada Tabel 5 berikut.

Tabel 4. Hasil pengukuran tanah latosol

\begin{tabular}{ccccc}
\hline No & Waktu Percobaan & Kelembaban Tanah $(\%)$ & Suhu Tanah $\left({ }^{\circ} \mathrm{C}\right)$ & Pompa \\
\hline \multirow{2}{*}{1} & \multirow{2}{*}{08.00 WIB } & Percobaan $1=45 \%$ & Percobaan $1=27,00^{\circ} \mathrm{C}$ & ON \\
& \multirow{2}{*}{09.00 WIB } & Percobaan $2=74 \%$ & Percobaan $2=27,00^{\circ} \mathrm{C}$ & OFF \\
2 & \multirow{2}{*}{10.00 WIB } & Percobaan $1=45 \%$ & Percobaan $1=29,80^{\circ} \mathrm{C}$ & ON \\
& Percobaan $1=45 \%$ & Percobaan $1=30,90^{\circ} \mathrm{C}$ & ON \\
3 & Percobaan 2 $=73 \%$ & Percobaan $2=30,00^{\circ} \mathrm{C}$ & OFF \\
\hline No & Waktu Percobaan & Kelembaban Tanah $(\%)$ & Suhu Tanah $\left({ }^{\circ} \mathrm{C}\right)$ & Pompa \\
\hline \multirow{2}{*}{4} & 11.00 WIB & Percobaan $1=45 \%$ & Percobaan $1=33,44^{\circ} \mathrm{C}$ & ON \\
5 & 12.00 WIB & Percobaan 2 $=73 \%$ & Percobaan $2=33,00^{\circ} \mathrm{C}$ & OFF \\
\hline
\end{tabular}




\begin{tabular}{|c|c|c|c|c|}
\hline & & Percobaan $2=76 \%$ & Percobaan $2=33,69^{\circ} \mathrm{C}$ & OFF \\
\hline \multirow{2}{*}{6} & \multirow{2}{*}{$13.00 \mathrm{WIB}$} & Percobaan $1=47 \%$ & Percobaan $1=30,50^{\circ} \mathrm{C}$ & $\mathrm{ON}$ \\
\hline & & Percobaan $2=85 \%$ & Percobaan $2=30,44^{\circ} \mathrm{C}$ & OFF \\
\hline \multirow{2}{*}{7} & \multirow{2}{*}{$14.00 \mathrm{WIB}$} & Percobaan $1=42 \%$ & Percobaan $1=29,81^{\circ} \mathrm{C}$ & $\mathrm{ON}$ \\
\hline & & Percobaan $2=86 \%$ & Percobaan $2=28,19^{\circ} \mathrm{C}$ & OFF \\
\hline \multirow{2}{*}{8} & \multirow{2}{*}{$15.00 \mathrm{WIB}$} & Percobaan $1=42 \%$ & Percobaan $1=28,00^{\circ} \mathrm{C}$ & $\mathrm{ON}$ \\
\hline & & Percobaan $2=78 \%$ & Percobaan $2=27,94^{\circ} \mathrm{C}$ & OFF \\
\hline \multirow{2}{*}{9} & \multirow{2}{*}{$16.00 \mathrm{WIB}$} & Percobaan $1=44 \%$ & Percobaan $1=26,94^{\circ} \mathrm{C}$ & $\mathrm{ON}$ \\
\hline & & Percobaan $2=81 \%$ & Percobaan $2=26,87^{\circ} \mathrm{C}$ & OFF \\
\hline \multirow{2}{*}{10} & \multirow{2}{*}{$17.00 \mathrm{WIB}$} & Percobaan $1=47 \%$ & Percobaan $1=26,25^{\circ} \mathrm{C}$ & $\mathrm{ON}$ \\
\hline & & Percobaan $2=76 \%$ & Percobaan $2=26,00^{\circ} \mathrm{C}$ & OFF \\
\hline
\end{tabular}

Grafik perbandingan hasil variabel tersebut dapat ditunjukkan pada Gambar 7. Hasil pengujian kelembaban pada tanah latosol menurun dengan bertambahnya waktu. Saat nilai kelembaban yang terbaca berkurang, maka sistem melakukan penyiraman sehingga nilai kelembaban akan naik sesuai kebutuhan tanaman.

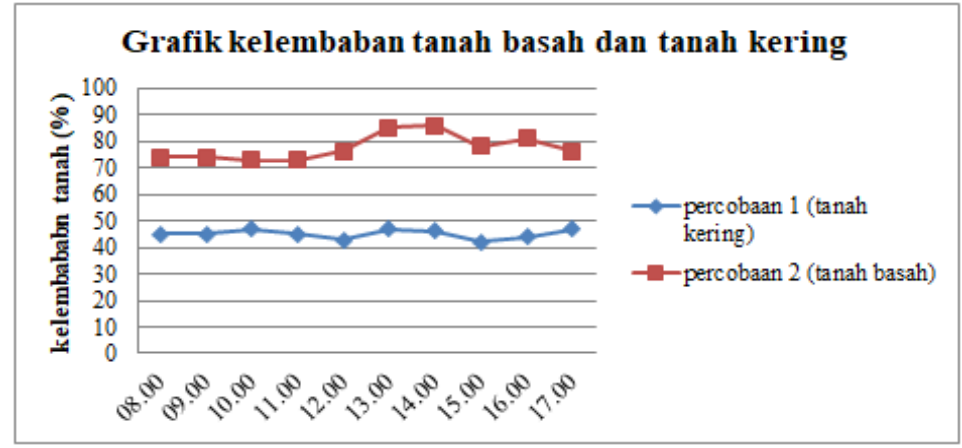

Gambar 7. Grafik kelembaban tanah basah dan tanah kering

Grafik perbandingan suhu tanah basah dan tanah kering dapat ditunjukkan pada Gambar 8. Perubahan suhu yang terkandung pada tanah mengalami kenaikan pada saat pukul 12.00 sampai pukul 13.00. Dengan melakukan penyiraman, suhu yang terkandung dalam tanah berkurang, meskipun tidak signifikan.

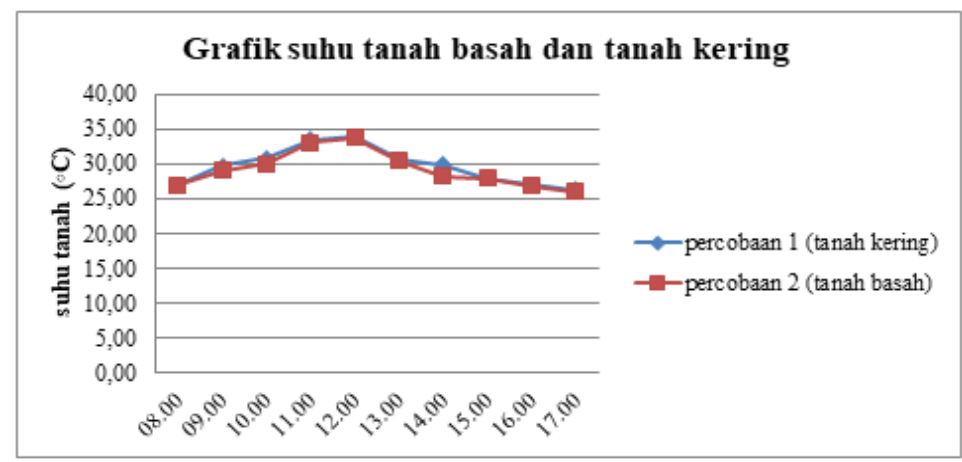

Gambar 8. Grafik suhu tanah basah dan tanah kering

\subsubsection{Perbandingan kelembaban tanah aluvial dan tanah latosol}

Perbandingan pengujian dari jenis tanah aluvial dan tanah latosol dapat dilihat pada Tabel 6. Hasil analisis pengujian dalam waktu satu jam dengan keadaan cuaca yang cerah, diperoleh nilai kelembaban jenis tanah aluvial cenderung lebih tidak mudah kering sehingga presentase kelembaban hampir tetap terjaga. Oleh karena itu, penggunaan jenis tanah aluvial lebih cocok untuk tanaman bawang merah. Pengujian untuk jenis tanah latosol cenderung mudah kering. Saat melakukan pengujian dalam waktu satu jam, jenis tanah latosol harus membutuhkan penyiraman yang rutin agar nilai kelembaban yang dibutuhkan tanaman bawang merah agar tetap terjaga pada kelembaban $50 \%-70 \%$. 
Tabel 5. Perbandingan kelembaban tanah aluvial dan tanah latosol

\begin{tabular}{|c|c|c|c|}
\hline No & $\begin{array}{c}\text { Waktu } \\
\text { Percobaan }\end{array}$ & $\begin{array}{c}\text { Kelembaban } \\
\text { Tanah Aluvial (\%) }\end{array}$ & $\begin{array}{c}\text { Kelembaban } \\
\text { Tanah Latosol }(\%)\end{array}$ \\
\hline \multirow{2}{*}{1} & \multirow{2}{*}{$08.00 \mathrm{WIB}$} & Percobaan $1=37 \%$ & Percobaan $1=45 \%$ \\
\hline & & Percobaan $2=69 \%$ & Percobaan $2=74 \%$ \\
\hline \multirow{2}{*}{2} & \multirow{2}{*}{$09.00 \mathrm{WIB}$} & Percobaan $1=49 \%$ & Percobaan $1=45 \%$ \\
\hline & & Percobaan $2=68 \%$ & Percobaan $2=74 \%$ \\
\hline \multirow{2}{*}{3} & \multirow{2}{*}{$10.00 \mathrm{WIB}$} & Percobaan $1=47 \%$ & Percobaan $1=45 \%$ \\
\hline & & Percobaan $2=72 \%$ & Percobaan $2=73 \%$ \\
\hline \multirow{2}{*}{4} & \multirow{2}{*}{$11.00 \mathrm{WIB}$} & Percobaan $1=48 \%$ & Percobaan $1=45 \%$ \\
\hline & & Percobaan $2=77 \%$ & Percobaan $2=73 \%$ \\
\hline \multirow{2}{*}{5} & \multirow{2}{*}{$12.00 \mathrm{WIB}$} & Percobaan $1=48 \%$ & Percobaan $1=43 \%$ \\
\hline & & Percobaan $2=73 \%$ & Percobaan $2=76 \%$ \\
\hline \multirow{2}{*}{6} & \multirow{2}{*}{$13.00 \mathrm{WIB}$} & Percobaan $1=40 \%$ & Percobaan $1=47 \%$ \\
\hline & & Percobaan $2=78 \%$ & Percobaan $2=85 \%$ \\
\hline \multirow{2}{*}{7} & \multirow{2}{*}{$14.00 \mathrm{WIB}$} & Percobaan $1=46 \%$ & Percobaan $1=42 \%$ \\
\hline & & Percobaan $2=66 \%$ & Percobaan $2=86 \%$ \\
\hline \multirow{2}{*}{8} & \multirow{2}{*}{$15.00 \mathrm{WIB}$} & Percobaan $1=48 \%$ & Percobaan $1=42 \%$ \\
\hline & & Percobaan $2=74 \%$ & Percobaan $2=78 \%$ \\
\hline \multirow{2}{*}{9} & \multirow{2}{*}{$16.00 \mathrm{WIB}$} & Percobaan $1=47 \%$ & Percobaan $1=44 \%$ \\
\hline & & Percobaan $2=75 \%$ & Percobaan $2=81 \%$ \\
\hline \multirow{2}{*}{10} & \multirow{2}{*}{ 17.00 WIB } & Percobaan $1=49 \%$ & Percobaan $1=47 \%$ \\
\hline & & Percobaan $2=61 \%$ & Percobaan $2=76 \%$ \\
\hline
\end{tabular}

\subsubsection{Perbandingan suhu tanah aluvial dan tanah latosol}

Hasil perbandingan pengukuran suhu tanah aluvial dan tanah latosol dapat dilihat pada Tabel 7. Analisis hasil pengujian suhu dari kedua jenis tanah dengan jangka waktu pengukuran satu jam, didapatkan untuk suhu pada jenis tanah aluvial lebih stabil untuk mencukupi batasan minimal ataupun maksimal untuk presentase suhu tanah yang harus dipenuhi untuk tanaman bawang merah agar hasil tanaman maksimal. Sedangkan untuk jenis tanah latosol hasil pengukuran pada pukul 12.00 dihasilkan pengukuran dengan nilai suhu tanah sebesar $35,00{ }^{\circ} \mathrm{C}$ hal ini dikarenakan jenis tanah latosol lebih kering sehingga suhu tanah naik, dengan melakukan penyiraman maka suhu tanah akan menurun.

Tabel 6. Perbandingan suhu tanah aluvial dan tanah latosol

\begin{tabular}{|c|c|c|c|}
\hline No & $\begin{array}{c}\text { Waktu } \\
\text { Percobaan }\end{array}$ & $\begin{array}{c}\text { Suhu } \\
\text { Tanah Aluvial }\left({ }^{\circ} \mathrm{C}\right) \\
\end{array}$ & $\begin{array}{c}\text { Suhu } \\
\text { Tanah Latosol }\left({ }^{\circ} \mathrm{C}\right)\end{array}$ \\
\hline \multirow{2}{*}{1} & \multirow{2}{*}{$08.00 \mathrm{WIB}$} & Percobaan $1=28,12^{\circ} \mathrm{C}$ & Percobaan $1=27,00^{\circ} \mathrm{C}$ \\
\hline & & Percobaan $2=28,12^{\circ} \mathrm{C}$ & Percobaan $2=27,00^{\circ} \mathrm{C}$ \\
\hline \multirow{2}{*}{2} & \multirow{2}{*}{$09.00 \mathrm{WIB}$} & Percobaan $1=31,94^{\circ} \mathrm{C}$ & Percobaan $1=29,80^{\circ} \mathrm{C}$ \\
\hline & & Percobaan $2=31,50^{\circ} \mathrm{C}$ & Percobaan $2=29,05^{\circ} \mathrm{C}$ \\
\hline \multirow{2}{*}{3} & \multirow{2}{*}{$10.00 \mathrm{WIB}$} & Percobaan $1=30,33^{\circ} \mathrm{C}$ & Percobaan $1=30,90^{\circ} \mathrm{C}$ \\
\hline & & Percobaan $2=30,00^{\circ} \mathrm{C}$ & Percobaan $2=30,00^{\circ} \mathrm{C}$ \\
\hline \multirow{2}{*}{4} & \multirow{2}{*}{$11.00 \mathrm{WIB}$} & Percobaan $1=32,67^{\circ} \mathrm{C}$ & Percobaan $1=33,44^{\circ} \mathrm{C}$ \\
\hline & & Percobaan $2=32,56^{\circ} \mathrm{C}$ & Percobaan $2=33,00^{\circ} \mathrm{C}$ \\
\hline \multirow{2}{*}{5} & \multirow{2}{*}{$12.00 \mathrm{WIB}$} & Percobaan $1=33,00^{\circ} \mathrm{C}$ & Percobaan $1=35,00^{\circ} \mathrm{C}$ \\
\hline & & Percobaan $2=32,75^{\circ} \mathrm{C}$ & Percobaan $2=34,70^{\circ} \mathrm{C}$ \\
\hline \multirow{2}{*}{6} & \multirow{2}{*}{$13.00 \mathrm{WIB}$} & Percobaan $1=31,81^{\circ} \mathrm{C}$ & Percobaan $1=30,50^{\circ} \mathrm{C}$ \\
\hline & & Percobaan $2=31,62^{\circ} \mathrm{C}$ & Percobaan $2=30,44^{\circ} \mathrm{C}$ \\
\hline \multirow{2}{*}{7} & \multirow{2}{*}{$14.00 \mathrm{WIB}$} & Percobaan $1=29,37^{\circ} \mathrm{C}$ & Percobaan $1=29,81^{\circ} \mathrm{C}$ \\
\hline & & Percobaan $2=29,31^{\circ} \mathrm{C}$ & Percobaan $2=28,19^{\circ} \mathrm{C}$ \\
\hline \multirow{2}{*}{8} & \multirow{2}{*}{$15.00 \mathrm{WIB}$} & Percobaan $1=28,19^{\circ} \mathrm{C}$ & Percobaan $1=28,00^{\circ} \mathrm{C}$ \\
\hline & & Percobaan $2=28,12^{\circ} \mathrm{C}$ & Percobaan $2=27,94^{\circ} \mathrm{C}$ \\
\hline \multirow{2}{*}{9} & \multirow{2}{*}{$16.00 \mathrm{WIB}$} & Percobaan $1=27,69^{\circ} \mathrm{C}$ & Percobaan $1=26,94^{\circ} \mathrm{C}$ \\
\hline & & Percobaan $2=27,50^{\circ} \mathrm{C}$ & Percobaan $2=26,87^{\circ} \mathrm{C}$ \\
\hline \multirow{2}{*}{10} & \multirow{2}{*}{$17.00 \mathrm{WIB}$} & Percobaan $1=27,25^{\circ} \mathrm{C}$ & Percobaan $1=26,25^{\circ} \mathrm{C}$ \\
\hline & & Percobaan $2=27,20^{\circ} \mathrm{C}$ & Percobaan $2=26,00^{\circ} \mathrm{C}$ \\
\hline
\end{tabular}




\section{KESIMPULAN}

Sistem ini menggunakan sensor soil moisture dan sensor DS18B20 untuk mendeteksi kelembaban dan suhu tanah. Penyiraman pada tanah tanaman bawang merah terjadi apabila kelembaban yang dibaca oleh sensor soil moisture di bawah 50\%. Jika pengukuran sudah mencapai $70 \%$, maka water pump akan berhenti menyiram. Pada saat pengujian jenis tanah, hasil menunjukkan perbedaan yang cukup signifikan. Penggunaan jenis tanah aluvial lebih cocok untuk tanaman bawang merah jika dibandingkan jenis tanah latosol yang cenderung mudah kering.

\section{DAFTAR PUSTAKA}

[1] Firmansyah, I., \& Sumarni, N. (2013). Pengaruh dosis pupuk N dan varietas terhadap pH tanah, N-total tanah, serapan $\mathrm{N}$, dan hasil umbi bawang merah (Allium ascalonicum L.) pada tanah entisols-Brebes Jawa Tengah. Jurnal Hortikultura, 23(4), 358-364.

[2] Thaker, M. A., Markana, B. B., \& Bhanderi, R. H. (2017). Automatic Soil Moisture and Temperatur Detector. Electronics \& Telecommunication, 284-286.

[3] Sumarni, N., \& Hidayat, A. (2005). Budidaya Bawang Merah. Bandung: Balai Penelitian Sayuran.

[4] Sutarya, R., \& Grubben, G. (1995). Pedoman bertanam sayuran dataran rendah.

[5] Lutfiyana, L., Hudallah, N., \& Suryanto, A. (2017). Rancang bangun alat ukur suhu tanah, kelembaban tanah, dan resistansi. Jurnal Teknik Elektro, 9(2), 80-86. 
